\title{
O Brasil frente ao conflito regional na América Central: oposição ao intervencionismo e apoio à solução negociada, justa, equilibrada e duradoura (1979-1996)
}

\section{CARLOS FEDERICO DOMÍNGUEZ AVILA*}

“Quando os homens lutam, os deuses intervêm.” Homero

\section{Introdução}

Entre 1979 e 1996, teve lugar, na América Central, um conflito regional violento e extremamente complexo. Esse conflito regional terminou provocando expressivas reações entre diferentes atores ou agentes da sociedade internacional. Mais ainda, tais reações não se limitaram aos meios estritamente governamentais - ou exclusivamente diplomáticos. Pelo contrário, um considerável número de atores não-governamentais e da sociedade civil - incluindo certas organizações de classe, o mundo acadêmico, as instituições religiosas, parlamentares, entre outros - não deixaram de exercer "pressão" ante os respetivos governos para que esses formulassem e implementassem políticas exteriores frente ao conflito regional em questão, congruentes com as suas próprias percepções, interpretações e interesses. Nessa ordem de idéias, o propósito deste artigo é explorar e compreender a lógica inerente à política brasileira frente ao conflito regional na América Central.

Em termos gerais, as fontes documentais, sobretudo as fontes do Arquivo Histórico do Ministério das Relações Exteriores (AHMRE), sugerem que a política brasileira frente ao conflito regional imperante na América Central orientou-se por um conjunto coerente, persistente e construtivo de ponderações. Tais ponderações terminaram dando lugar ao que aqui se chamará de "tese brasileira" sobre a origem, a evolução e os possíveis mecanismos de resolução para o conflito regional. 
Convém agregar, ainda, que a relativamente bem sucedida pacificação e a democratização da América Central, em grande medida sob os auspícios dos processos negociadores de Contadora, primeiro, e de Esquipulas, depois, também terminaram confirmando a validez do pregado pela assim chamada "tese brasileira".

\section{Alguns antecedentes do relacionamento brasileiro-centro-americano durante o século $\mathrm{XX}$}

As relações econômicas, políticas e culturais entre o Brasil e os cinco países da América Central - termo que se refere à Guatemala, El Salvador, Honduras, Nicarágua e Costa Rica -, durante o século XX, demostram uma tendência orientada para uma gradual convergência de interesses, cordialidade e fortalecimento dos diferentes vínculos. De fato, trata-se de um relacionamento quase-centenário, amistoso, construtivo e promissor; porém, que ainda na atualidade continua sendo relativamente modesto. O professor José Carlos Brandi Aleixo (1983: 22), que é um dos principais acadêmicos brasileiros que tem estudado as tendências do relacionamento brasileiro-centro-americano, atribuiu essa situação, entre outras causas, a:

as distâncias geográficas; a inexistência ou precariedade dos meios de transporte e comunicação; a vinculação excessiva das colônias com suas metrópoles; a escassez de informação mútua sobre a história, a geografia, a economia, a política e a cultura de modo geral; a ausência por muito tempo de Legações com Ministros residentes nos respectivos países; a diferença de línguas; etc. Consequentemente a presença do Brasil na América Central e da América Central no Brasil, particularmente até a primeira metade deste século [XX], é muito limitada.

Em sendo assim, parece pertinente agregar que entre 1906, quando o Brasil estabeleceu relações diplomáticas com as nações da América Central, e o 25 de junho de 1979, quando o governo do Presidente João Batista de Oliveira Figueiredo decidiu suspender as relações diplomáticas com o desacreditado regime nicaragüense comandado pelo general Anastasio Somoza Debayle, o relacionamento brasileiro-centro-americano pode ser analisado em três subperíodos, os quais, salvo melhor juízo, podem ser definidos como: (a) os contatos iniciais (1906-1950); (b) o fortalecimento das relações diplomáticas plenas (19501971); e c) a intensificação das relações econômicas e políticas (1971-1979).

Durante o período dos contatos iniciais as partes começaram a interagir. Particularmente expressiva terminou sendo, nesse sentido, a Terceira Conferência Internacional Americana, celebrada na cidade do Rio de Janeiro, entre os dias 23 de julho e 27 de agosto de 1906. De fato, Aleixo $(1983,1984)$ sublinha que tal acontecimento impulsionou um relacionamento mais estreito e duradouro, dado que até então os vínculos políticos, econômicos ou culturais eram praticamente 
nulos. E, três meses após o conclave, o Presidente Augusto Moreira Pena autorizou a abertura de uma Legação brasileira para os governos de Cuba e das nações da América Central.

A partir de então, e durante a maior parte do século XX, a política brasileira frente às nações do istmo centro-americano - incluindo os outros dois subperíodos supracitados - caraterizou-se pelo surgimento de um conjunto de regularidades, que não deixaram de repercutir na formulação e implementação da política de Brasília frente ao conflito regional em questão.

No plano político-diplomático e estratégico, por exemplo, a política brasileira aparentemente reconheceu certa preponderância dos interesses estratégicos dos Estados Unidos na Bacia do Caribe, em geral, e na América Central, em particular (Burns, 1966). Isso derivou em uma virtual relação triangular brasileiro-centroamericana-estadunidense, na qual a política da potência média (Brasil) frente às potências menores (países da América Central) terminou sendo definida não somente por tópicos essencialmente bilaterais ou pressões domésticas, mas também pela avaliação das visões, aspirações e prioridades da potência hegemônica do continente (os Estados Unidos ). Convém agregar que essa articulação entre a potência hegemônica do continente, a potência média e as pequenas potências foi particularmente clara durante a primeira metade do século XX, quando o governo brasileiro implementou uma política essencialmente de baixo perfil e uma atitude relativamente discreta e complacente frente ao intervencionismo - inclusive frente ao intervencionismo militar - do governo estadunidense em várias das nações localizadas na Bacia do Caribe, argumentando-se que o Brasil não tinha interesses nacionais vitais naquela região (Burns, 1966; Cervo e Bueno, 2002; Camargo, 1985). Cabe registrar que a cooperação brasileiro-estadunidense com relação à Bacia do Caribe alcançou o zênite na controvertida intervenção conjunta na República Dominicana, em 1965 (Moniz Bandeira, 1998; Reiner, 1987; Moniz Bandeira, 1999; Aleixo, 1987).

Durante os decênios de 1960 e 1970, o relacionamento brasileiro-centroamericano foi favorecido pelas convergências ideológicas - anticomunistas preponderantes nos regimens autoritários imperantes nesses países (com a notável exceção do caso da Costa Rica). Tais coincidências político-ideológicas entre governos autoritários, junto à tradicional cordialidade e normalidade no relacionamento entre as partes, traduziu-se no oferecimento de oportunidades de estudo para oficiais centro-americanos em academias militares brasileiras, a possibilidade de exportação de material de emprego militar de fabricação brasileira para os países do istmo, o apoio mútuo de candidaturas em organismos internacionais, a constante denúncia das alegadas tendências subversivas do regime revolucionário cubano (e de outros países de orientação socialista), etc. De fato, em 1973, o então embaixador brasileiro em Manágua, Milton Faria, chegou a qualificar o ditador nicaragüense, Anastasio Somoza Debayle, como "nosso amigo”, 
dado que, argumentou-se, "representa no Continente uma enorme barreira, o único obstáculo aos anseios da extrema esquerda [sic]." Em contrapartida, os governos autoritários do istmo centro-americano expressaram de forma reiterada, pública e definitiva a simpatia e identificação com o projeto sócio-político-econômico dos herdeiros da assim chamada "revolução brasileira" de 1964.

No plano econômico e comercial, o relacionamento brasileiro-centroamericano, caraterizou-se por dois aspetos básicos - vigentes ainda na atualidade. De um lado, nas convergências de interesses no tocante à defesa dos preços do café - e também do açúcar - no mercado internacional, dado que os países em questão são importantes fornecedores do produto. De fato, a coordenação das políticas cafeeiras e a mútua verificação da adscrição e respeito pelas respectivas cotas de exportação pactuadas foram (e continuam sendo) tópicos expressivos na agenda econômica entre as partes.

Por outro lado, o outro motivo que estimulou a intensificação das relações econômicas foi o persistente interesse dos exportadores brasileiros por penetrar no mercado da América Central. Desse modo o comércio entre os países começou a tomar certo vigor. Inicialmente, os produtos brasileiros com maior demanda potencial no istmo foram têxteis finos, produtos farmacêuticos, eletrodomésticos e produtos odontológicos.

Em contraste, as exportações centro-americanas para o Brasil continuaram sendo virtualmente nulas. Isso, devido, entre outras razões, a que todos os produtos que os países centro-americanos exportavam ao mercado internacional (café, banana, carne, algodão, açúcar, etc.) eram essencialmente agrícolas e, também, eram praticamente os mesmos que o Brasil produzia com a mesma finalidade. De fato, as agroexportações brasileiras e centro-americanas normalmente terminavam competindo entre si no mercado internacional. Daí os elementos mais característicos e duradouros do relacionamento econômico brasileiro-centroamericano, entre outros: (i) a considerável assimetria na pauta comercial; (ii) a ausência de complementaridade no intercâmbio; (iii) os problemas logísticos; (iv) o caráter relativamente modesto do montante e volume do intercâmbio; e (v) o perturbador e persistente superávit na balança comercial em favor do Brasil.

Antes de concluir a presente epígrafe é pertinente agregar dois acontecimentos no relacionamento brasileiro-centro-americano recente: a visita do chanceler Mário Gibson Barbosa às nações do istmo (em 1971) e a suspensão das relações diplomáticas entre o Brasil e a Nicarágua (em 1979).

A visita do Chanceler Gibson Barbosa foi um acontecimento sumamente importante nas relações bilaterais do Brasil com cada um dos países do istmo centro-americano. Note-se que era a primeira vez, na história das relações internacionais contemporâneas da América Latina e do Caribe, que um representante diplomático brasileiro de tão alto nível recorria às nações centroamericanas. Em cada um dos cinco países, o Chanceler Gibson Barbosa foi 
recebido pelas máximas autoridades. Assinaram-se cinco Declarações Conjuntas, ademais dos respectivos discursos (Aleixo, 1983a).

As Declarações Conjuntas foram muito parecidas. No âmbito político, as partes destacaram: a "tradicional e estreita amizade" entre o Brasil e cada um dos países da América Central; o compartilhado respeito pelos princípios do Direito Internacional que regem (ou deveriam reger) nas relações internacionais; o respaldo à participação ativa das partes nos foros multilaterais (ONU, OEA, Cecla, Unctad, etc.); a condenação ao terrorismo; o estímulo à cooperação e solidariedade interamericana; a criação de Comissões Mistas; etc.

No âmbito econômico, as Declarações Conjuntas abordaram a necessidade de insistir ante os países industrializados em prol da implementação de sistemas de preferências generalizados não recíprocos nem discriminatórios em favor dos países em desenvolvimento; o reconhecimento dos direitos do mar (200 milhas de uso exclusivo, etc.); a proteção dos preços de produtos básicos (café, etc.); a intensificação das relações comerciais entre os países membros do Mercado Comum Centro-Americano (MCCA) e da Associação Latino-Americana de Livre Comércio (Alalc); o apoio financeiro para a importação de produtos brasileiros mediante a abertura de linhas de crédito por um valor de US\$1 milhão para cada um dos países da América Central; a inauguração de linhas de transporte marítimo; etc.

Ademais, no âmbito cultural, colocou-se a necessidade de ampliar e aprofundar os intercâmbios científicos e artísticos, assim como a implementação de programas de assistência técnica mediante o oferecimento de bolsas para que estudantes da América Central pudessem ingressar nas universidades brasileiras.

Em termos mais amplos e de longo prazo, a visita do Chanceler Gibson Barbosa à América Central pode ser interpretada como outra das conseqüências das significativas transformações econômicas e sócio-políticas que o capitalismo brasileiro estava experimentando no contexto do chamado "milagre econômico" (1969-1973). Sob essa perspectiva, não parece incorreto sugerir que o Brasil estava procurando consolidar a sua presença comercial em mercados pouco explorados, principalmente o africano, mas também o da América Latina e do Caribe, entre outros, levando em conta as facilidades tecnológicas "tropicalizadas" oferecidas pelos exportadores brasileiros. Também, procurava estabelecer relações internacionais com base em objetivos próprios, com ênfases na necessidade de promover o crescimento econômico e insistindo na possibilidade de impulsionar relações mais equilibradas e justas entre os países industrializados do Norte e as nações em desenvolvimento do Sul (Cervo e Bueno, 1992: Capítulo 15; Vizentini, 1998; Moniz Bandeira, 1999: Capítulos VII e VIII; Lima, 1990).

Ao mesmo tempo, a visita do Chanceler Gibson Barbosa à América Central pode ser interpretada como conseqüência do alegado declínio do poder hegemônico dos Estados Unidos na região e, portanto, como uma oportunidade 
para redefinir os acordos tácitos entre brasileiros e estadunidenses surgidos no primeiro terço do século XX sobre as respectivas políticas frente à Bacia do Caribe, com maior benefício comercial e político para os primeiros. A partir dessa perspectiva, a Bacia do Caribe deixaria de ser uma região de hegemonia exclusiva dos Estados Unidos, afirmação duvidosa desde o triunfo e consolidação da elite revolucionária cubana, abrindo as condições e possibilidades para que "potências industriais emergentes”, como o Brasil, conseguissem construir um espaço para alcançar objetivos próprios - de natureza econômica, política e estratégica - nessa e em outras regiões do mundo (Moniz Bandeira, 1999).

Paralelamente, a suspensão das relações diplomáticas brasileironicaragüenses, por iniciativa do governo do Presidente Figueiredo, foi um acontecimento extremamente significativo e um antecedente direto da política brasileira frente ao conflito regional na América Central.

Efetivamente, em 25 de junho de 1979, o governo brasileiro anunciou a suspensão das relações diplomáticas com o governo da Nicarágua. Lamentavelmente, os documentos consultados no Arquivo Histórico do Ministério das Relações Exteriores (AHMRE) não explicam a lógica burocrática que determinou a tomada de uma decisão tão grave e pouco usual. Contudo, tal documentação oferece pistas que permitem fazer uma reconstrução dos acontecimentos. Nesse sentido, a decisão de romper com o agonizante regime do general Somoza Debayle pode ter sido tomada - salvo melhor juízo - com base em quatro ponderações básicas: (a) o acelerado processo de desgaste internacional do regime somozista; (b) a continuidade (e algumas sutis mudanças) implementadas na política exterior pelo novo governo brasileiro, encabeçado pelo general João Batista de Oliveira Figueiredo (1979-1985); (c) as pressões do Parlamento brasileiro; e (d) o exemplo costarriquenho, mexicano e de outros países latinoamericanos e caribenhos.

Em termos gerais, não parece incorreto ponderar que Brasília teria suspendido as relações diplomáticas com o desacreditado governo do general Somoza Debayle devido ao acelerado processo de deterioração da situação interna e internacional da Nicarágua somozista. As grosseiras e sistemáticas violações aos direitos humanos do povo da Nicarágua foi a razão central que justificou a convocatória da XVII Reunião de Consulta da OEA (entre 1978 e 1979). As resoluções dessa reunião terminaram colocando o regime de Manágua, virtualmente, na ilegalidade. Nesse contexto, o governo brasileiro teria interrompido as suas relações com a Nicarágua para acelerar a queda do regime e agradar às futuras autoridades do país. Adicionalmente, vale realçar que tanto a mentalidade "pragmática” herdada pela diplomacia brasileira como as "pressões” procedentes do Parlamento e o exemplo de outros países latino-americanos e caribenhos foram fatores importantes na resposta de Brasília frente à crise terminal do governo somozista. Obviamente, tais ponderações são antecedentes importantes para 
compreender e interpretar as reações iniciais do Brasil frente ao emergente conflito regional na América Central, que é o que mais interessa para os fins do presente artigo.

Em suma, a partir de uma perspectiva temporal mais abrangente, parece adequado reiterar que, durante o século XX, as relações Brasil-América Central foram essencialmente corretas, porém modestas. Essa situação é possível atribuirse tanto à ausência de interesses nacionais vitais do Brasil no istmo (e vice-versa), como a um fator estratégico sumamente importante que é a presunção hegemônica dos Estados Unidos entre os países da Bacia do Caribe (incluindo a América Central). Por essas e outras razões, a política centro-americana do Brasil, a partir da "era Rio Branco" (1902-1912), teria evitado se imiscuir nos assuntos da Bacia do Caribe, em geral, e da América Central, em particular. Tratar-se-ia, então, de uma virtual relação triangular entre brasileiros, centro-americanos e estadunidenses. Isso é parte do fundamento do que Bradford Burns (1966) chamou de a "aliança não escrita” entre os Estados Unidos e o Brasil. Também, uma interpretação especulativa e indireta sobre a natureza, a lógica e as políticas que têm orientado as relações Brasil-América Central durante a maior parte do século XX. Ao mesmo tempo, parece importante sublinhar que com base em tais considerações é possível compreender e interpretar a evolução do relacionamento brasileiro-centroamericano a partir de 1979.

\section{O conflito regional na América Central, no contexto global da Segunda Guerra Fria: brevíssima análise}

Como dito, entre 1979 e 1996, teve lugar na América Central um conflito regional, que pode - ou deve - ser estudado sob a perspetiva da história da Segunda Guerra Fria (1979-1989). Convém ressaltar que a noção de Segunda Guerra Fria - termo acunhado pelo historiador britânico Fred Halliday (1986) - alude à complexa articulação de ambientes, interpretações teóricas e políticas de Estado que provocaram ou foram conseqüência da notória intensificação de tensões, competição e conflito globalizado imperante nas relações internacionais entre dezembro de 1979 - quando os países membros da Otan determinaram o incremento dos orçamentos de defesa e a instalação de mísseis de alcance intermediário, por um lado, e ocorreu a intervenção militar direta dos soviéticos no Afeganistão, por outro lado - e novembro de 1989 - queda do muro de Berlim. A periodização da história da Segunda Guerra Fria inclui uma fase de bipolaridade rígida (19791985) e outra fase de bipolaridade flexível (1985-1979).

Entretanto, o termo conflito regional, que é sumamente importante para os fins deste artigo, alude a uma situação de aguda tensão e conflito armado gerado pela interação complexa entre fatores locais (e sub-regionais), por um lado, e influências, aspirações e pressões hegemônicas extra-regionais, por outro. 
Sendo que a interação entre pressões endógenas e exógenas ameaçou comprometer o envolvimento das duas superpotências da época, os Estados Unidos e a União Soviética, seja direta ou indiretamente (por meio dos seus respectivos aliados). Note-se, assim, a expressiva importância da lógica e das políticas inspiradas na confrontação, competição e tensão próprias da bipolaridade estratégica, política, econômica e ideológica, isto é, a lógica da Segunda Guerra Fria, que dominou a evolução da sociedade internacional entre 1979 e 1989. Portanto, um conflito regional supõe (ou supôs durante o decênio de 1980) a "internacionalização" ou "globalização" de uma crise local ou sub-regional, pela articulação de fatores essencialmente endógenos com pressões e aspirações hegemônicas de potências continentais e globais. $^{2}$

Com tais antecedentes conceituais em mente, vale notar que as origens e a evolução do conflito regional imperante na América Central a partir da segunda metade do decênio de 1970 apresentaram conotações endógenas e exógenas.

Sob o ponto de vista endógeno, parece evidente que houve na América Central dos anos setenta a gradual passagem do "inaceitável” para o "insuportável” - isto é, "o que viola a dignidade humana” (Duroselle, 2000: 194ss). A ordem econômica e sócio-política imperante nas nações do istmo a partir da implantação das assim chamadas reformas liberais de fins do século XIX começou a ser nova e vigorosamente questionada por diferentes atores ou agentes - inclusive por "novos" movimentos de libertação nacional. Vale recalcar que tal questionamento do essencialmente injusto, desequilibrado e autoritário estilo de (sub)desenvolvimento econômico e sócio-político - imperante durante demasiado tempo e em benefício de uns poucos privilegiados - originou-se, fundamentalmente, por pressões endógenas.

Em outras palavras, a dimensão endógena do conflito regional na América Central sugere que se tratou da relação dialética entre o desejo dos povos de superar a injustiça social, o autoritarismo político e a notória iniqüidade na distribuição da renda, por um lado, e a natural resistência do assim chamado "bloco histórico no poder” dominante nos países do istmo - particularmente na Guatemala, El Salvador e Nicarágua -, por outro lado (Rouquié, 1994). Ou, como afirmou categoricamente o Deputado Federal Aluízio Bezerra (PMDB-AC), na Câmara dos Deputados do Brasil, no dia 11 de março de 1982, tratava-se da contradição entre "as forças que querem a liberdade, a independência, o desenvolvimento objetivo e emancipador, contra os que querem a continuação da miséria, da opressão e do retrocesso social."3

Assim, uma série de transformações econômicas e sócio-políticas incluindo o surgimento de movimentos de libertação nacional, como a Frente Sandinista de Libertação Nacional (FSLN), a Frente Farabundo Martí de Libertação Nacional (FMLN) e a Unidade Revolucionária Nacional Guatemalteca (URNG) - terminaram fazendo do istmo uma das regiões mais conflituosas do mundo. O triunfo da revolução popular sandinista na Nicarágua (em julho de 1979) e a 
reativação das forças insurgentes em El Salvador e na Guatemala marcaram o estopim de um conjunto de tensões e conflitos armados, que somente se concluiriam depois da (surpreendente) derrota eleitoral dos sandinistas (em fevereiro de 1990) e da assinatura e aplicação dos compromissos de paz firme e duradoura pactuados - sob os auspícios dos processos negociadores de Contadora, primeiro, e Esquipulas, depois - em El Salvador (1992) e na Guatemala (1996). Sendo, ademais, que a Costa Rica e Honduras, apesar de não experimentarem diretamente o drama da guerra civil, também sofreram os rigores emanados da lógica e das políticas próprias do conflito regional. ${ }^{4}$

Em suma, a dimensão regional do conflito regional na América Central alude fundamentalmente à complexa articulação dos seguintes tópicos específicos: (a) conflitos armados internos em El Salvador, na Guatemala e na Nicarágua sandinista (guerra dos “contras”, anti-sandinistas financiados pelo governo dos Estados Unidos ); (b) grave crise econômica e social nos cinco países, reflexo da chamada "década perdida" no desenvolvimento latino-americano e caribenho; e (c) complexos processos de transição do autoritarismo para a democracia em quatro dos cinco países do istmo.

Por sua vez, a dimensão exógena do conflito regional demanda uma análise nas suas especificidades centro-americana, continental e global - cada uma delas “encadeadas” ou articuladas entre si e com a dimensão endógena.

A dimensão especificamente centro-americana do conflito regional referese às tensões e divergências provocadas pelas mútuas acusações de intervenção nos assuntos internos dos Estados vizinhos, pelo apoio - legal ou ilegal - oferecido a atores ou agentes afins (governos internacionalmente reconhecidos, forças irregulares, etc.) nos outros países. Tal apoio incluiu respaldo político-diplomático, militar, financeiro, de propaganda, ideológico, entre outros.

Particularmente complexa terminou sendo a convivência entre o governo da Nicarágua sandinista, por um lado, e os ideologicamente conservadores governos imperantes nos países vizinhos, por outro. De fato, Manágua acusou seus vizinhos, particularmente Costa Rica, Honduras e El Salvador, de apoiarem a controversa luta dos assim chamados "contras" (também respaldados pelos governos dos Presidentes Ronald Reagan e George Bush). Entretanto, os vizinhos da Nicarágua denunciavam os possíveis vínculos do governo sandinista com forças insurgentes que operavam na região - sobretudo com as guerrilhas da FMLN, em El Salvador -, configurando um aparente intento de “exportação da revolução”. Convém agregar que a dimensão especificamente centro-americana do conflito regional, ainda que com dificuldade, conseguiu manter-se no caus das divergências políticas e diplomáticas - evitando-se, assim, a escalada de um aberto e dramático conflito armado regional.

A dimensão continental do conflito regional refere-se à participação de atores de outros países americanos (sobretudo latino-americanos) e seu impacto 
no conflito em questão. De fato, desde muito cedo, os governos - bem como atores não-governamentais e da sociedade civil - de diferentes Estados latinoamericanos e caribenhos identificaram-se e apoiaram, com diferentes meios (políticos, diplomáticos, financeiros, ideológicos e inclusive militares), a diferentes agentes que operavam no istmo. Nesse sentido, particularmente relevantes foram os casos do México, da Venezuela, de Cuba, da Argentina, do Panamá, da Colômbia e do Chile, além do caso brasileiro.

Vale ressaltar que, a partir da criação do chamado Grupo de Contadora (em janeiro de 1983), ${ }^{5}$ a grande maioria dos governos da região e do mundo optaram por respaldar a capacidade negociadora desse grupo, orientada para a busca de uma solução negociada, justa, equilibrada e duradoura para o conflito. E, em 1985, integrou-se o chamado Grupo de Apoio ao processo negociador de Contadora, com a participação dos governos da Argentina, do Brasil, do Peru e do Uruguai.

Sob a perspetiva da história das relações internacionais contemporâneas da América Latina e do Caribe, o processo negociador de Contadora (vigente sobretudo entre 1983 e 1986) erigiu-se em uma extraordinária experiência de concertação e coordenação política entre Estados (Frohmann, 1990). Note-se que a iniciativa multilateral de mediação em questão caraterizou-se pelo seu estrito apego ao direito internacional, o seu convincente diagnóstico das causas e da evolução do conflito regional, uma nova "praxis" na metodologia de resolução de conflitos, entre outras ponderações. Os esforços político-diplomáticos dos países latino-americanos enquadrados no processo negociador de Contadora, ainda que não foram coroados com a assinatura da "Ata de Contadora para a paz e cooperação na América Central” - devido à feroz e persistente oposição da potência hegemônica do continente -, conseguiram conter a lógica do conflito, abrir canais de comunicação e negociação, influir no processo negociador de Esquipulas dirigido pelos próprios governos da América Central - e preparar as condições que permitiram a criação do Mecanismo Permanente de Consulta e Concertação Política ou Grupo do Rio (Grio).

Entretanto, a dimensão global do conflito regional refere-se à intervenção de potências e atores extra-regionais, entre outros: as superpotências da época, a ONU, certos países europeus. O controvertido intervencionismo das superpotências, especialmente dos Estados Unidos durante as duas administrações do Presidente Ronald Reagan (1981-1989), terminou agudizando os conflitos latentes (Carpenter, 1986; Rouquié, 1994; Gleijeses,1986; Aleixo, 1987). Sem esquecer que o caso da estratégia de conflito de baixa intensidade implementada pelo governo dos Estados Unidos contra a revolução sandinista e contra forças insurgentes em El Salvador, Guatemala e Honduras foi motivo de muito debate, inclusive na Corte Internacional de Justiça.

Contudo, acontecimentos tais como o escândalo Irã-“contras”, o "novo pensamento” de política exterior soviética da “era Gorbachëv”, a queda do muro 
de Berlim, entre outros importantes fatos mundiais, terminaram não só com a lógica e com as políticas inerentes da Segunda Guerra Fria, como também ofereceram mais favoráveis condições e possibilidades para que os atores envolvidos diretamente nos conflitos conseguissem resolvê-los pacificamente. Nesse sentido, é compreensível que, a partir de 1986, os próprios governos, movimentos insurgentes e outros atores do istmo conseguissem, no marco do assim chamado processo negociador de Esquipulas, autonomamente, chegar a acordos relevantes. Tais acordos, cujo eixo orientava-se para a simultânea pacificação e democratização das diferentes sociedades da região, permitiram colocar fim a uma situação de conflito, destruição e morte.

A relativamente bem sucedida pacificação e democratização das nações da América Central - ainda que padecendo de certos percalços, contradições e limitações - é uma conquista extremamente relevante sob a perspectiva da história das relações internacionais contemporâneas da América Latina e do Caribe. Sem esquecer que o Brasil, junto a outros países do subcontinente, persistentemente demandou tanto a restrição das - antijurídicas e imorais - aspirações e pressões hegemônicas e intervencionistas das superpotências, como uma saída negociada, justa, equilibrada e duradoura para o conflito regional em questão.

\section{A “tese brasileira” sobre a origem, a evolução e os possíveis mecanismos de resolução para o conflito regional imperante na América Central: em busca de uma caraterização da lógica da política centro-americana do Brasil durante os perturbadores anos da Segunda Guerra Fria}

Em termos gerais, as fontes, sobretudo as fontes primárias resgatadas no Arquivo Histórico do Ministério das Relações Exteriores (AHMRE), sugerem que a política externa brasileira frente ao conflito regional imperante na América Central, entre 1979 e 1996, formulou-se e implementou-se através de um conjunto relativamente permanente de critérios que, coletivamente, deram lugar ao que aqui se tem chamado de "tese brasileira” sobre a origem, a evolução e os possíveis mecanismos de resolução para o conflito regional no istmo.

A "tese brasileira” sobre o conflito regional na América Central terminou erigindo-se em uma espécie de marco conceitual da política centro-americana de Brasília. A mesma surgiu e evoluiu mediante a tensão entre seis ponderações básicas (documentalmente verificáveis):

\section{a) A constatação do caráter estrutural e sistêmico do conflito}

Assim, por exemplo, em 1983, entre as instruções à delegação brasileira que iria participar da XXXVIII Sessão da Assembléia Geral da ONU, expressouse, entre outras considerações, que "os problemas da América Central derivam 
de causas históricas, relacionadas com a manutenção de estruturas econômicas desequilibradas e socialmente injustas, e se vinculam à crise econômica mundial”. Ressaltando, em seguida, que tais problemas no istmo "não podem, portanto, ser considerad[o]s apenas do ângulo da confrontação ideológica ou do recurso a soluções de força” ${ }^{6}$. Em um outro documento confidencial interno do Itamaraty, de 1989, afirma-se, categoricamente, que "a avaliação básica [do Governo brasileiro] é a de que a crise centro-americana tem raízes estruturais, históricas, sócio-econômicas e culturais" ${ }^{7}$. Sem esquecer que o chanceler Ramiro Saraiva Guerreiro, em conferência sobre política externa global brasileira na Escola Superior de Guerra, em agosto de 1984, afirmou que:

Com relação à América Central, a política brasileira ao longo dos últimos cinco anos esteve sempre balizada pela diretriz central de buscar uma solução negociada para os problemas regionais.

Na avaliação brasileira, a crise regional tem raízes estruturais, inscritas no processo de evolução política e econômica da América Central, e sua superação estaria condicionada à adoção de medidas destinadas a promover o desenvolvimento econômico, a justiça social e o pluralismo político na região. De outro lado, é fundamental que sejam afastadas todas as formas de interferência externa no encaminhamento das questões regionais. A interferência externa agrava as dificuldades locais, estimula soluções de força e a transferência de tensões globais bloqueia a ação da diplomacia. ${ }^{8}$

Em conseqüência, parece claro que, para Brasília, a origem, a natureza e a evolução do conflito regional na América Central - ao fundamentar-se no ineqüitativo, desequilibrado e excludente estilo de desenvolvimento econômico e sócio-político imperante durante demasiado tempo - deveria ser resolvido, não através de medidas de força, mas, sim, assumindo os agudos problemas econômicos, políticos e sociais que têm levado a região a uma situação de desenvolvimento humano bastante precária (com a possível exceção do caso costarriquenho).

\section{b) A necessidade de procurar uma saída negociada e congruente com os princípios do Direito Internacional}

Durante todo o decênio de 1980 - assim como na ordem internacional pós-Segunda Guerra Fria -, Brasília considerou que "a base para o entendimento está, de um lado, na busca do diálogo construtivo e da solução pacífica de controvérsias e, de outro, no respeito aos princípios e propósitos da Carta da ONU (não-uso da força, direito à independência, integridade territorial e soberania dos Estados, e a não-ingerência em seus assuntos internos)" ${ }^{9}$ O governo brasileiro insistiu, paralelamente, em que a busca das soluções, que por certo deveriam ser negociadas e pacíficas, correspondia basicamente aos próprios governos (e outros atores) do istmo. 
“A posição do Governo brasileiro, no tocante à crise centro-americana, obedece às linhas gerais de nossa política externa: estrita observância dos princípios fundamentais expressos na Carta das Nações Unidas, em particular os relativos à autodeterminação dos povos e à não-ingerência nos assuntos internos de outros países. Dessa forma, a solução pacífica das controvérsias representa, segundo a ótica brasileira, a única solução viável para os conflitos regionais”, informou-se confidencialmente, em 1984, à delegação brasileira que participaria da correspondente Assembléia Geral da ONU. ${ }^{10}$

Mais ainda, as autoridades brasileiras persistentemente demandaram de todos os atores internacionais com vínculos e interesses no conflito regional na América Central um estrito apego aos princípios fundamentais do Direito Internacional - especialmente no que corresponde ao devido respeito ao princípio da não-intervenção nos assuntos internos de outros Estados (Aleixo, 1987). Na prática, isso se traduziu na rejeição e na oposição frente à transferência para a América Central da lógica e das políticas inspiradas na competição, tensão e confrontação Leste-Oeste que caracterizou a Segunda Guerra Fria e o questionamento das aspirações e pressões hegemônicas das superpotências.

\section{c) A favorável predisposição para participar-ativa e solidariamente - de iniciativas multilaterais sérias e construtivas em favor da pacificação do istmo}

De fato isto se traduziu no persistente, significativo e solidário respaldo político-diplomático do Brasil aos processos negociadores de Contadora, primeiro, e de Esquipulas, depois. Convém ressaltar que a partir dos albores do decênio de 1980, as autoridades brasileiras, segundo documentação disponível no Itamaraty, consideraram importante colaborar com aqueles países mais diretamente envolvidos nos labores mediadores em busca de uma eventual saída negociada para o conflito regional, especialmente quando se tratava de iniciativas diplomáticas mexicanas e venezuelanas. Nesse sentido, não parece estranho que o Brasil também terminasse oferecendo seu respaldo político-diplomático aos atores mais diretamente envolvidos na busca da paz, da cooperação e da segurança no istmo, tanto no marco do processo negociador de Contadora como de Esquipulas.

Em relação a Contadora, parece conveniente ressaltar que, segundo uma declaração conjunta brasileiro-mexicana, assinada em março de 1984, pelos Presidentes João Figueiredo e Miguel de la Madrid Hurtado, “O Presidente do Brasil reiterou o apoio decidido e solidário de seu Governo a esses esforços e assinalou que o Grupo de Contadora constitui a única alternativa política e ética para a solução dos problemas centro-americanos”11.

Mais ainda, em um documento confidencial de agosto de 1984, reconheceuse que "A Iniciativa de Contadora, ainda que padecendo de limitações práticas 
para a consecução da paz, é vista pelo Brasil, como a única alternativa interregional a uma solução de força. É exatamente nesse sentido que temos expressado com clareza nossa posição solidária à capacidade negociadora do grupo"12.

Sob esse ponto de vista, parece "natural” que, depois do retorno à ordem constitucional (em 1985), as autoridades brasileiras aceitassem participar de maneira direta - como parte do Grupo de Apoio, do Mecanismo Permanente de Consulta e Concertação Política ou Grupo do Rio (Grio), da OEA, da ONU, etc. - nos processos negociadores de Contadora e Esquipulas, procurando, vale insistir, uma saída política, justa, equilibrada, honrosa e duradoura para o conflito regional na América Central.

Note-se que "pressões” internas, que se bem não parece prudente exagerar mas tampouco desdenhar ou desconhecer, também puderam ter exercido certa influência na (re)formulação da "tese brasileira”. Efetivamente, organizações sindicais, instituições religiosas, movimentos populares, partidos políticos, o mundo acadêmico, etc., não deixaram de demandar de governos e da diplomacia do Itamaraty uma política congruente com a lógica dos processos negociadores de Contadora, primeiro, e de Esquipulas, depois. Isso foi bastante claro no debate parlamentar.

d) Aoposição frente às aspirações hegemônicas e ao intervencionismo de potências extra-regionais, assim como à transferência das tensões, competição e confrontação entre as superpotências à América Central

Aqui parece importante ressaltar que as autoridades brasileiras especialmente durante os mandatos dos Presidentes João Figueiredo (cujo governo, entre 1979 e 1985, coincidiu com a fase de bipolaridade rígida da Segunda Guerra Fria) e José Sarney (cujo governo, entre 1985 e 1990, coincidiu com a fase de bipolaridade flexível da Segunda Guerra Fria) - expressaram uma persistente, sistemática e categórica oposição frente às aspirações e pressões hegemônicas de ambas as superpotências na América Central e em outros conflitos regionais no Terceiro Mundo.

Ao mesmo tempo, e sob uma perspectiva de longo prazo, a oposição e o questionamento das autoridades brasileiras frente às (espúrias) aspirações e pressões hegemônicas das superpotências na América Central, em particular, e na América Latina (e no Terceiro Mundo), em geral, formou parte não só da "tese brasileira”, mas também de uma decisão estratégica coletiva que culminou com a revitalização da solidariedade intralatino-americana e caribenha e a criação do Mecanismo Permanente de Consulta e Concertação Política ou Grupo do Rio (Grio), que surgiu como um derivado do processo negociador de Contadora. 
e) O reconhecimento da limitada influência do Brasil nos acontecimentos sócio-políticos, econômicos e estratégicos imperantes na América Central

Uma análise equilibrada, serena, objetiva e realista da evolução do relacionamento brasileiro-centro-americano não deve ignorar o fato de que durante a maior parte do século XX e, particularmente, no contexto da Segunda Guerra Fria, o Brasil, ao contrário de outras nações latino-americanas e caribenhas como o México, a Venezuela, Cuba, a Argentina, a Colômbia, o Panamá, o Chile, etc. - com mais intensos e expressivos vínculos e interesses econômicos, políticos e estratégicos na América Central, nunca estiveram em jogo ou em risco interesses nacionais vitais no istmo.

Certamente isso terminou influenciando no "cálculo estratégico" das autoridades brasileiras frente ao conflito regional, criando, por momentos, certas ambigüidades, dúvidas e tensões sobre a verdadeira tendência e natureza da política centro-americana de Brasília. Um bom exemplo disso foram as (polêmicas) transferências de material de emprego militar de fabricação brasileira - dotado de “responsabilidade política irrecusável do Governo do país exportador, em virtude de suas consequiências no relacionamento entre as nações adversárias"13 - para Honduras (aviões EMB-312 Tucano) e para os “contras” nicaragüenses (fuzis, munições, etc.).

f) O reconhecimento das graves conseqüências internas e externas em todos os países do hemisfério - inclusive no próprio Brasil que poderiam ser desencadeadas pelo agravamento das tensões no istmo

A documentação resgatada no Arquivo Histórico do Ministério das Relações Exteriores (AHMRE) também sugere que os "homens de Estado" encarregados da política centro-americana de Brasília expressaram, durante todo o decênio de 1980, preocupação pelas “incalculáveis” e "imprevisíveis" conseqüências domésticas e globais que poderiam ser desatadas na hipótese de uma "vietnamização" da América Central, causada pela intervenção militar direta de alguma potência extra-regional - leia-se estadunidense e, em muito menor medida, cubano-soviética.

Efetivamente, as fontes sugerem que, para as autoridades políticas e diplomáticas brasileiras, a evolução do conflito regional na América Central era motivo de intranqüilidade e temor dado que um "cenário vietnamita” no istmo para não considerar as (apocalípticas) conseqüências globais de uma escalada que desembocasse em uma guerra nuclear total, o que não podia ser descartado 
especialmente durante a fase de bipolaridade rígida da Segunda Guerra Fria poderia provocar ou agudizar a polarização ideológica das forças políticas locais e repercutir negativamente no sensível e delicado processo de transição à democracia no próprio Brasil e em outras nações do subcontinente.

Essas ponderações, que parecem ser demasiado utópicas, foram efetivamente consideradas por não poucos atores brasileiros e estrangeiros. Nesse sentido, o apoio político-diplomático do Brasil a Contadora e Esquipulas também poderia ser interpretado sob a perspectiva da incipiente governabilidade democrática do país. Em outras palavras, não parece exagerado sugerir que o respaldo político-diplomático de Brasília a Contadora e Esquipulas poderia ser entendido como uma espécie de "diplomacia preventiva”, que respondeu, de certo modo e a longo prazo, aos interesses nacionais do país. Talvez por isso o Chanceler Roberto de Abreu Sodré, ao analisar a evolução do processo negociador de Contadora em conferência ditada na Escola Superior de Guerra, no dia 27 de junho de 1986, afirmasse que:

Se, por um lado, é forçoso reconhecer que não houve avanços decisivos e definitivos no processo [negociador] de Contadora, não há como negar a extrema importância da iniciativa ao impedir que se crie um vazio diplomático na crise e que o conflito [regional na América Central] possa agravar-se ainda mais, transformando-se em conflagração de repercussões imprevisíveis para todo o Continente americano. Contadora deve ser avaliada não apenas pelo que de bom fez, ou deixou de fazer, mas também pelo que de mal e desastroso tem evitado que aconteça. ${ }^{14}$

Então, levando em conta a lógica da "tese brasileira" sobre a origem, a evolução e os possíveis mecanismos de resolução para o conflito regional na América Central, parece possível compreender e interpretar, de maneira global e integral a "leitura", os fundamentos e as tendências que caracterizaram a evolução da política centro-americana de Brasília.

Sob a óptica da "tese brasileira“, parece congruente, construtivo, lógico e coerente o apoio político-diplomático de Brasília aos processos negociadores de Contadora e Esquipulas. De fato, é possível identificar certas afinidades entre a “tese brasileira”, por um lado, e a lógica e as políticas inerentes a Contadora e Esquipulas, por outro, devido a: (i) o caráter genuinamente latino-americano e caribenho de Contadora e especificamente centro-americano de Esquipulas, sem esquecer a continuidade entre ambos os processos de negociação; (ii) o apego de ambos os processos de negociação aos princípios básicos do Direito Internacional; (iii) a utilização de uma filosofia de trabalho - incluindo os correspondentes métodos e técnicas de resolução de conflitos - que, estimou-se no Itamaraty, eram essencialmente corretos, coerentes e apropriados para encarar, de maneira global, 
os complexos problemas econômicos, sócio-políticos e estratégicos da América Central; e,(iv) o reconhecido prestígio e a considerável legitimidade internacional de ambos os processos de negociação - o que foi simbolicamente expresso, entre outras coisas, na adjudicação do muito significativo Prêmio Nobel da Paz ao Presidente costarriquenho Oscar Arias Sánchez (em 1987) e à cidadã guatemalteca Rigoberta Menchú Tum (em 1992).

Em termos operacionais, o respaldo brasileiro a Contadora e Esquipulas se traduziu em uma série de gestos, declarações e ações diplomáticas concretas, seja unilateral ou multilateralmente - neste caso, principalmente, por meio da incorporação ao Grupo de Apoio a Contadora ou da ativa participação em foros diplomáticos tais como o Mecanismo Permanente de Consulta e Concertação Política ou Grupo do Rio (Grio), a ONU, a OEA, etc. Esses atos se cristalizaram em significativas determinações de cunho político-diplomático, tais como: (a) o Brasil foi o segundo país do mundo a expressar oficialmente apoio diplomático ao recém-criado Grupo de Contadora (em 1983); (b) participou do Grupo de Apoio a Contadora; (c) integrou o Grupo do Rio (Grio); (d) formou parte do mecanismo de verificação e seguimento emanado do “Acordo de Esquipulas II”; (e) emitiu uma série de documentos oficiais - unilaterais, bilaterais e multilaterais - nos quais se expressou firme apoio para Contadora e Esquipulas e vigoroso questionamento frente às (espúrias) aspirações e pressões hegemônicas das superpotências; (f) ofereceu significativa assistência técnica, científica, cultural e econômica, apesar da complexa conjuntura econômica e social do país, agravada pelos perversos efeitos da assim chamada "década perdida"; e, (g) no marco do processo de Esquipulas, o Brasil participou de todas as operações de manutenção da paz da ONU na América Central (Onuven, Onuca, Onusal, Minugua, etc.), e de iniciativas comparáveis da OEA (Marminca, etc.), fosse com peritos civis ou militares.

Naturalmente, esses e outros exemplos são extremamente significativos sob a perspectiva da "tese brasileira", em particular, e da história das relações internacionais contemporâneas da América Latina e Caribe, em geral. Parece evidente que tais gestos, iniciativas, declarações e ações concretas caracterizam um compromisso sincero, construtivo, exemplar, digno, honroso, solidário e imperecível, cujo impacto no relacionamento brasileiro-centro-americano é (e continuará sendo) extremamente significativo. Isso é ainda mais relevante ao constatar-se que, até 1979, o relacionamento brasileiro-centro-americano era bastante limitado.

Portanto, parece lícito concluir que a relativamente bem sucedida pacificação e democratização da América Central, apesar de certas ambigüidades, dificuldades, percalços e imprevistos no cumprimento de alguns compromissos pactuados, muito particularmente no que se refere à completa "desmilitarização das sociedades”, também significou a plena confirmação da “tese brasileira”. 


\section{O futuro do relacionamento brasileiro-centro-americano: procurando uma relação mais estreita, equilibrada e construtiva}

A relativamente bem sucedida pacificação e democratização da América Central no marco dos processos negociadores de Contadora e Esquipulas, junto à positiva, solidária e construtiva conduta da política exterior brasileira frente ao conflito regional, deixou entrever uma ampla margem para aprofundar, intensificar e expandir os diferentes vínculos, sejam esses econômicos, político-diplomáticos ou culturais.

No plano econômico e comercial, o relacionamento brasileiro-centroamericano, que nunca foi muito intenso, não deixou de ser afetado negativamente pela "década perdida" e especialmente pelos efeitos dissociadores da lógica e das políticas que caraterizaram a história da Segunda Guerra Fria.

Paralelamente, no campo comercial, o mais notório e persistente no relacionamento Brasil-América Central, desde antes do decênio de 1980, tem sido, vale insistir: a grande assimetria na pauta comercial, a ausência de complementaridade nas trocas, os problemas logísticos, o caráter modesto do valor e volume do intercâmbio, e o constante e perturbador superávit na balança comercial em favor do Brasil (e, conseqüentemente, dado o caráter estrutural do desequilíbrio no balanço de pagamentos, em prejuízo das economias centro-americanas). Por essas e outras razões, entre 1979 e 1994, o intercâmbio comercial brasileiro-centroamericano tem sido claramente favorável para o lado brasileiro (veja-se Quadro 1 da pág. seguinte).

Vale agregar que, de acordo com os periódicos relatórios para o Itamaraty procedentes das Embaixadas brasileiras acreditadas ante os governos dos cinco países do istmo, os principais produtos exportados pelo Brasil com destino aos países da América Central, durante os decênios de 1980 e 1990, incluíam: (a) maquinaria e equipamento de construção; (b) meios de transporte (veículos, ônibus, barcos, etc.); (c) maquinaria agrícola; (d) produtos químicos (fertilizantes, etc.); (e) papel; (f) artigos elétricos e eletrônicos; (g) material médico-hospitalar; (h) equipamento de oficina; (i) brinquedos; entre outros. Nesse sentido, tratava-se essencialmente de bens de capital e bens de consumo duráveis. Tais produtos eram importados por governos e empresas privadas do istmo diretamente junto a exportadores brasileiros (sendo que em alguns casos foram abertas representações comerciais de empresas brasileiras em alguns países do istmo).

Em contrapartida, as importações brasileiras de produtos centroamericanos continuaram sendo extremamente limitadas, e mesmo insignificantes. Isso devido, entre outras razões, a que a maior parte dos produtos exportados pela América Central - que são principalmente produtos agroindustriais -, não só também são produzidos no Brasil, como em vários casos terminam competindo entre si no mercado internacional. ${ }^{15}$ Em todo caso, durante o decênio de 1980, 


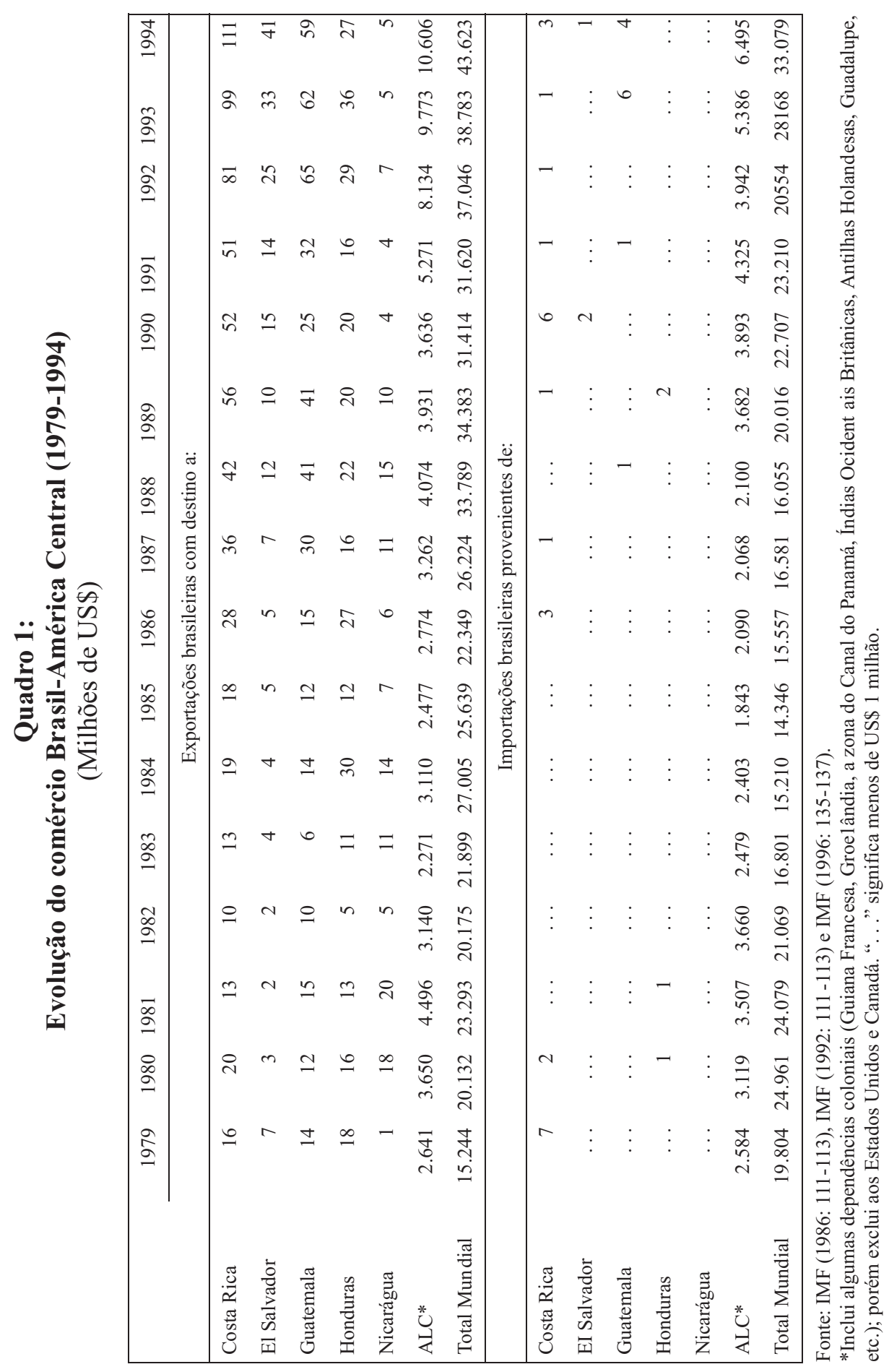


sobressaiu-se a exportação para o mercado brasileiro de sementes oleaginosas da Costa Rica e sementes de árvores florestais e frutíferas de Honduras.

Sob o ponto de vista do financiamento, o relacionamento brasileiro-centroamericano durante o decênio de 1980 beneficiou-se com a abertura de linhas de crédito do Banco do Brasil para os cinco países do istmo, ressaltando que a Nicarágua terminou sendo o país mais favorecido, já que a sua linha de crédito alcançou um valor total de US\$50 milhões.

Ademais, um dos compromissos emanados da primeira reunião cimeira de presidentes do Mecanismo Permanente de Consulta e Concertação Política ou Grupo do Rio (Grio), na cidade mexicana de Acapulco (em novembro de 1987), foi o incentivo para que os países membros, no marco da Aladi, oferecessem às nações do istmo a oportunidade de negociar Acordos de Alcance Parcial (AAP). Isso com a finalidade de facilitar o aceso dos produtos centro-americanos aos mercados do Brasil e dos outros países membros do Grio, e, ao mesmo tempo, com propósito de criar estímulos para as economias do istmo - limitando, assim, as tensões econômicas e sócio-políticas imperantes em cada um deles no contexto do conflito regional.

Contudo, em termos mais abrangentes, parece evidente que o relativo sucesso da pacificação e democratização da América Central no marco do processo negociador de Esquipulas e a participação brasileira no mesmo foram fatores importantes para explicar, ao menos parcialmente, o notório incremento das relações econômicas entre as partes durante a primeira metade do decênio de 1990 .

Segundo estatísticas sobre tendências de comércio internacional do Fundo Monetário Internacional (IMF, 1996), entre 1990 e 1994, o valor das exportações brasileiras para o istmo cresceu consideravelmente nos casos da Costa Rica (de US\$52 milhões a US\$111 milhões), da Guatemala (de US\$25 milhões a US\$59 milhões) e de El Salvador (de US\$15 milhões a US\$41 milhões). Também incrementou-se, embora de maneira menos expressiva, o valor das exportações brasileiras com destino a Honduras (de US\$20 milhões a US\$27 milhões) e Nicarágua (de US\$4 milhões a US\$5 milhões). No entanto, o valor das importações brasileiras de produtos centro-americanos continuou sendo notoriamente limitado (veja-se Quadro 1).

Um importante desafio, portanto, para o presente e para o futuro das relações econômicas brasileiro-centro-americanas é procurar reduzir essa relação assimétrica e estruturalmente deficitária para as economias do istmo.

Dentre as alternativas para conseguir alcançar, gradualmente, um comércio reciprocamente mais vantajoso podem incluir-se as seguintes: (a) a promoção de inversões conjuntas que permitam a capitais brasileiros satisfazer demandas reprimidas das economias da região como também aproveitar as vantagens comparativas da América Central com relação a terceiros mercados (levando em consideração as facilidades fiscais concedidas pelos governos centro-americanos 
e as condições e possibilidades oferecidas pelos acordos de livre comércio e outros tratamentos preferenciais concedidos aos países do istmo centro-americano por economias com mercados mais expressivos, principalmente nos Estados Unidos, no México, no Canadá, na União Européia, etc.); (b) o financiamento e participação de empresas construtoras do Brasil em projetos de infra-estrutura econômica e social na América Central; (c) uma maior abertura do mercado brasileiro para os produtos centro-americanos; (d) a organização de eventos de promoção comercial que permitam a aproximação de produtores e consumidores de ambos os lados; entre outros.

Nesse sentido, possivelmente a firma do Acordo Marco de Comércio e Inversão, de abril de 1998, entre autoridades do Mercosul e do Sistema de Integração Centro-Americano (Sica), contribua com aquela finalidade. Note-se que dito acordo Mercosul-Sica prevê, entre outras coisas, a criação de uma Comissão de Comércio e Inversões, cujo propósito básico é, justamente, explorar as condições e possibilidades para uma dinamização das relações econômicas entre ambos os processos de integração. Convém agregar que tais acordos procuram promover um relacionamento comercial mais equilibrado e mutuamente vantajoso entre o Brasil e os países da América Central.

Finalmente, ainda no terreno das relações econômicas brasileiro-centroamericanas, parece importante destacar as convergências (e também as divergências) de interesses em torno do gerenciamento e da participação concertada das partes no mercado internacional do açúcar e, particularmente, do café. Isso, porque o Brasil e as nações centro-americanas continuam sendo alguns dos mais importantes exportadores mundiais do café e do açúcar, e que tais produtos continuam sendo fontes significativas de divisas para cada uma das partes.

No plano político (e cultural), o relacionamento entre as partes adquiriu uma dinâmica mais ativa a partir dos encontros entre autoridades políticas e diplomáticas do Brasil e da América Central, motivados pelo desejo comum de encontrar possíveis soluções negociadas para o conflito regional. Isso expressouse em uma série de visitas recíprocas de altas autoridades governamentais, em declarações, no apoio recíproco de iniciativas e candidaturas, e outras ações diplomáticas concretas.

Na atualidade a agenda política Brasil-América Central carateriza-se por uma alta e crescente convergência. Assim, por exemplo, a visita do ex-Presidente Fernando Henrique Cardoso à Costa Rica - e à América Central, em geral -, em abril de 2000, marcou um ponto de inflexão no relacionamento entre as partes. Em tal oportunidade, além do tratamento das questões estritamente bilaterais brasileiro-costariquenhas realizou-se a primeira reunião cimeira de Presidentes do Brasil e da América Central (que contou, ademais, com a presença de representantes dos governos da República Dominicana, do Panamá e de Belize) ${ }^{16}$. 
Da reunião cimeira de Presidentes, que de fato pode ser considerada como o acontecimento que abriu uma nova etapa no centenário relacionamento brasileiro-centro-americano, surgiu a muito importante Declaração de São José. Nesse documento, os Chefes de Estado e de Governo identificam, em linhas gerais, alguns dos critérios e prioridades econômicas, políticas e estratégicas que pautarão o relacionamento entre as partes nos alvores do século XXI. Dada a considerável relevância intrínseca do documento em apreço e a sua estreita relação com os fins do presente estudo, parece adequado introduzir uma breve análise do mesmo.

Na Declaração de São José, os mandatários do Brasil e da América Central pós-revolucionária reafirmaram "el compromiso de nuestros Gobiernos de estrechar los tradicionales lazos de amistad y cooperación existentes entre nuestros países y nuestro renovado empeño en intensificar los mecanismos de integración económica en América Latina y el Caribe”. Em seguida são enumerados onze tópicos ou pontos particularmente significativos na agenda brasileiro-centro-americana para o futuro próximo, que são: (a) a preservação e fortalecimento da Democracia; (b) a superação da pobreza e promoção do desenvolvimento sustentável; (c) a proteção do meio ambiente; (d) a promoção e proteção dos Direitos Humanos; (e) a manutenção da paz e da segurança internacionais; (f) a luta contra a corrupção, a narcoatividade, o terrorismo e os seus delitos conexos; (g) a inserção mais competitiva na economia internacional; (h) a crise financeira internacional; (i) o aperfeiçoamento dos mecanismos de integração e coordenação regional; (j) o fortalecimento do multilateralismo; e $(\mathrm{k})$ o fortalecimento da cooperação. Finalmente, no documento em apreço, as mais altas autoridades do Brasil e da América Central pós-revolucionária reafirmaram a "disposición de mantener consultas políticas en el nivel apropiado en todas las ocasiones en que sea posible, inclusive al margen de reuniones multilaterales o regionales".

Com base nessas ponderações, parece lícito concluir que a agenda brasileiro-centro-americana vigente é abrangente, multifacetada e relativamente sofisticada - especialmente se comparada com o limitado relacionamento político anterior a 1979. Mais ainda, na opinião do autor deste artigo, o novo governo brasileiro, dirigido pelo Presidente Luiz Inácio Lula da Silva, manterá as tendências de crescente e mais construtivo relacionamento político (e cultural) com as nações centro-americanas. Essa apreciação fundamenta-se não só no atual processo de globalização das economias (Cepal, 2002), na solvência moral e liderança do Presidente e do País no contexto latino-americano e caribenho, no constante contato pessoal entre os líderes políticos dos países ou pelo expressivo impacto e entusiasmo que despertou nos povos do istmo a categórica vitória eleitoral do Partido dos Trabalhadores nas eleições presidenciais do ano 2002, senão, também, pelo fato de que tanto o novo Presidente quanto vários dos seus mais próximos colaboradores - dentre esses, o atual Ministro da Educação, Cristovam Buarque - têm visitado pessoalmente a região centro-americana, em diferentes oportunidades. 
Por estas e outras ponderações, não parece totalmente incorreto afirmar que as condições e possibilidades para um relacionamento mais estreito, equilibrado, construtivo e duradouro são extremamente favoráveis. Nesse sentido, corresponde às partes - especialmente aos governos dos países da América Central - aproveitar a atual conjuntura das relações Brasil-América Central. Sem esquecer que, no ano 2006, poder-se-á comemorar de forma apropriada - talvez com uma nova reunião cimeira de Presidentes do Brasil e da América Central - o primeiro centenário de um relacionamento que, retomando as palavras do ex-chanceler Gibson Barbosa, "embora constante, ainda não ultrapassou os limites da eleição afetiva para fundamentar-se na solidariedade dos interesses, na coincidência do trabalho, no encontro dos esforços para um fim comum"17.

\section{Conclusão}

Entre 1979 e 1996, teve lugar na América Central um conflito regional complexo e violento. Esse conflito regional surgiu da articulação de fatores endógenos - entre outros: o ineqüitativo, excludente e autoritário estilo de desenvolvimento econômico e sócio-político imperante durante prolongado tempo no istmo (com exceção parcial do caso costarriquenho) - e exógenos - com destaque para o "encadeamento" de pressões globais, continentais e centroamericanas no contexto do que um conhecido historiador britânico chamou de Segunda Guerra Fria (1979-1989). Nessa ordem de idéias, o passo do "inaceitável” para o "insuportável” - quer dizer, "o que viola a dignidade humana” - transformou a América Central em uma das regiões mais conflituosas do planeta. Por essa e outras razões, os acontecimentos no istmo centro-americano passaram a ser objeto de intenso debate entre os mais diversos países (e no interior de cada um deles).

Entretanto, no Brasil, um país que então experimentava importantes transformações econômicas, sócio-políticas e de política internacional, o conflito regional na América Central não deixou de provocar expressivas repercussões. Mais ainda, tais repercussões não se limitaram aos meios governamentais (ou, especificamente, à burocracia diplomática). Pelo contrário, um considerável número de atores não-governamentais - que incluía o mundo acadêmico, o sindicalismo, certas instituições religiosas, alguns partidos políticos, etc. - também terminou expressando opiniões sobre o tema e "pressionando" governos e ao Itamaraty em favor de determinadas opções de política exterior. Isso ficou bastante claro no caso do debate parlamentar.

Com base em tais considerações e, muito especialmente, a partir da correspondente investigação básica no Arquivo Histórico do Ministério das Relações Exteriores (AHMRE), chega-se à conclusão geral de que a política brasileira, frente ao conflito regional na América Central, terminou dando lugar ao 
que aqui se chama de "tese brasileira" sobre a origem, a evolução e os possíveis mecanismos de resolução para o conflito regional imperante no istmo.

Note-se que essa "tese brasileira" sobre o conflito regional na América Central fundamenta-se com base em seis ponderações (documentalmente verificáveis): (a) a constatação do caráter estrutural e sistêmico do conflito; (b) a necessidade de procurar uma saída negociada e congruente com os princípios do Direito Internacional; (c) a favorável predisposição para participar mais ativamente de iniciativas multilaterais em favor da pacificação do istmo, de fato isso se traduziu no persistente, significativo e solidário respaldo político-diplomático do Brasil aos processos negociadores de Contadora, primeiro, e de Esquipulas, depois; (d) a oposição frente às aspirações hegemônicas e ao intervencionismo de potências extra-regionais, bem como à transferência das tensões, competição e confrontação entre as superpotências à América Central; (e) o reconhecimento da limitada influência do Brasil nos acontecimentos sócio-políticos, econômicos e estratégicos imperantes na América Central; e (f) o reconhecimento das graves conseqüências internas e externas em todos os países do hemisfério - inclusive no próprio Brasil - que poderiam ser desencadeadas pelo agravamento das tensões no istmo.

Adicionalmente, parece pertinente ressaltar que a dinâmica dos acontecimentos e a bem sucedida pacificação e democratização da América Central - em grande medida, sob os lineamentos dos processos negociadores de Contadora e Esquipulas -, de fato, terminaram convalidando, também, o pregado pela "tese brasileira”.

Abril de 2003

\section{Notas}

1 Milton Faria a Ministério das Relações Exteriores, Ofício confidencial-urgente, Manágua, 16.8.1973, AHMRE: Cx 20. Em janeiro de 1973, o Embaixador Faria informou aos seus superiores no Itamaraty que o terremoto que destruiu Manágua (em dezembro de 1972), traria graves conseqüências ideológicas e políticas - no caso de o presidente Anastasio Somoza Debayle ser derrocado. Segundo o representante diplomático brasileiro: "É evidente que ele [o general Somoza Debayle] cometeu erros, equívocos, mas sem ele muito difícil será a manutenção da ordem em toda a América Central, pois Nicarágua é o único obstáculo que impede a violenta propagação e penetração cubana [sic]”, Milton Faria a MRE, Ofício confidencial (SG/AAA/ DA), Manágua, 12.1.1973, AHMRE: Cx 20. Parecem óbvias as afinidades ideológicas e políticas do Embaixador brasileiro com o governo comandado pelo general Somoza. Vale inquirir se tais afinidades refletiam a posição oficial do Brasil frente ao governo da Nicarágua ou tratava-se de uma visão própria do pessoal diplomático brasileiro acreditado em Manágua. Para o autor deste estudo, a expressiva simpatia pelo governo do general Somoza Debayle do Embaixador Faria se refletia tanto no autoritarismo e conservadorismo do governo do general Emílio Garrastazu Médici, como nas convicções pessoais do diplomático em questão. 
2 Dentre os conflitos regionais no Terceiro Mundo mais importantes, no contexto global da Segunda Guerra Fria, vale ressaltar os seguintes: (a) América Central (Nicarágua, El Salvador, Guatemala, e com repercussões mais ou menos significativas em Granada, Cuba, Suriname, Colômbia, etc.); (b) África Meridional (Angola, Moçambique, Namíbia, África do Sul, Zaire, etc.); (c) noroeste da África (Saara Ocidental, Marrocos, Argélia, etc.); (d) o chifre da África (Etiópia, Somália, etc.); (e) Indochina (Camboja, Vietnã, China Tailândia, etc., também conhecida como a “Terceira Guerra da Indochina”); (f) Ásia Central (Afeganistão, URSS, Irã, Paquistão, China, etc.); até certo ponto, (g) nordeste da Ásia (península coreana), e (h) Oriente Médio (conflito palestino-israelita, Líbano, Líbia, guerra Irã-Iraque, etc.).

Aluízio BEZERRA, "Discurso do Sr. Deputado Aluízio Bezerra, proferido na sessão vespertina de 11-3-82”, Diário do Congresso Nacional, 13.3.1982, p. 876-879. Note-se que, no início do decênio de 1980, coexistiam em tensão três modelos diferentes de desenvolvimento econômico e sócio-político relativamente claros: (a) a democracia liberal na Costa Rica, (b) um regime revolucionário de “orientação socialista” na Nicarágua - que, ademais, impulsionava um poderoso "efeito demonstração" junto a outras forças revolucionárias no istmo, particularmente em El Salvador e na Guatemala -, e (c) o tradicional Estado autoritário na Guatemala, El Salvador e Honduras (ainda que neste último país acontecesse um acelerado processo de retorno à ordem constitucional). Duas décadas depois, no entanto, os países da região conseguiram erigir processo de democratização e pacificação relativamente bem sucedidos, porém que ainda precisam de maior coerência, solidez, efetividade e governabilidade democrática. Originalmente, o Grupo de Contadora foi integrado pelos governos da Colômbia, Panamá, México e Venezuela. O nome do grupo provém da ilha panamenha de Contadora, onde se realizou a primeira reunião dos chanceleres dos países membros do grupo. Em 1985, surgiu o Grupo de Apoio ao processo negociador de Contadora, integrado pelos governos da Argentina, Brasil, Peru e Uruguai.

6 “XXXVIIII Sessão da Assembléia-Geral das Nações Unidas/ Instruções Gerais”, Confidencial, Brasília, s.d. [circa, 1.9.1983], AHMRE: Cx 275.

7 José Vicente de Sá Pimentel a Chefe do DAA, Despacho ao Memorando DNU/60, Confidencialurgentíssimo, Brasília, 28.7.1989, AHMRE: Cx R-2.

8 Ramiro Saraiva GUERREIRO, “Conferência do Ministro de Estado das Relações Exteriores, Ramiro Saraiva Guerreiro, na Escola Superior de Guerra, no Rio de Janeiro, em 31 de agosto de 1984”, Resenha de Política Externa do Brasil, n. 42, p. 75-128.

9 “XXXVIIII Sessão da Assembléia-Geral das Nações Unidas/ Instruções Gerais”, Confidencial, Brasília, s.d. [circa, 1.9.1983], AHMRE: Cx 275.

10 Marco Antônio Diniz Brandão a Chefe, substituto, da DNU, Memorando confidencialurgente (DNU/85), Brasília, 10.8.1984, AHMRE: Cx M 2 (4).

11 "Declaração Conjunta Brasil-México, assinada, no Palácio do Planalto, em Brasília, em 30 de março de 1984, pelos Presidentes João Figueiredo e Miguel de la Madrid Hurtado”, Resenha de Política Externa do Brasil, n. 40; p. 44-52.

12 Marco Antônio Diniz Brandão a Chefe, substituto, da DNU, Memorando confidencialurgente (DNU/85), Brasília, 10.8.1984, AHMRE: Cx M 2 (4).

13 Antônio F. Azeredo da Silveira a Hugo de Andrade Abreu, Memorando secreto (DPG/DCS/ DSI), Brasília, s.d. [circa 12.5.1977], AHMRE: Pasta Especial PNEMEM-El Salvador.

14 "Palestra do Ministro de Estado das Relações Exteriores, Roberto de Abreu Sodré, na Escola Superior de Guerra, no Rio de Janeiro, em 27 de junho de 1986”, Resenha de Política Externa do Brasil, n. 49; p. 123-140.

15 A competição entre produtos brasileiros e centro-americanos no mercado internacional tem sido particularmente aguda no que diz respeito ao café, açúcar, frutas tropicais, têxteis, calçado, entre outros. 
16 “Declaración de San José”, São José, 5.4.2000, Ministerio de Relaciones Exteriores y Culto, na Internet: [www.rree.go.cr/Brasil-2000-Decl.html]. A “Declaração de São José”, foi assinada pelos Presidentes Fernando Henrique Cardoso, do Brasil; Mireya Moscoso, do Panamá; Miguel Angel Rodríguez Echeverría, da Costa Rica; Francisco Flores Pérez, de El Salvador; Carlos Roberto Flores Facusse, de Honduras; Arnoldo Alemán Lacayo, da Nicarágua; pelo Vice-Presidente Juan Francisco Reyes López, da Guatemala; pelo Primeiro Ministro Said Musa, de Belize; e pelo Chanceler Eduardo Latorre, da República Dominicana.

17 "Discurso do Ministro Mário Gibson Barbosa, ao fazer entrega, ao Ministro das Relações Exteriores da Guatemala, da Grã-Cruz da Ordem Nacional do Cruzeiro do Sul. Guatemala, em 13 de Julho”, Documentos de Política Externa V 1971, Brasília, Ministério das Relações Exteriores, 1973, p. 163-165.

\section{Fontes e Bibliografia}

a) Fontes primárias

Arquivo Histórico do Ministério das Relações Exteriores (AHMRE)

Diário do Congresso Nacional

Resenha de Política Externa do Brasil

b) Referências bibliográficas

ALEIXO, José Carlos Brandi. O Princípio de Não-Intervenção e sua Presença na História da América. Política e Estratégia, vol. V, n. 4 (out.-dez.), 1987; p. 506-528.

ALEIXO, José Carlos Brandi. O Brasil e a América Central, Brasília: Câmara dos Deputados/Comissão de Relações Exteriores, 1984.

ALEIXO, José Carlos Brandi. O Brasil e a América Central. Revista Brasileira de Política Internacional. n. 101-104, 1983, p. 21-58.

BRIGAGÃO, Clóvis. Brasil e América Central: Relações Políticas e Militares. Política e Estratégia. Vol. III, n. 2; 1985, p. 246-258.

BURNS, E. Bradford. At War in Nicaragua. The Reagan Doctrine and the Politicis of Nostalgia. New York: Horper and Row, 1987.

BURNS, E. Bradford. The Unwritten Alliance. Rio Branco and Brazilian-American Relations. New York: Columbia University Press, 1966.

CAMARGO, Sônia de. O Brasil em face da América Central e do Caribe. A História de uma ausência. Política e Estratégia. Vol. III, n. 2, 1985, p. 231-245.

CARPENTER, Ted Galen. U.S. Aid to anti-communist rebels: the 'Reagan Doctrine’ and its pitfalls. Policy Analisis, n. 74, 1986, na Internet: www.cato.org/pubs/pas/pa074.html. CEPAL. Globalização e desenvolvimento. Santiago do Chile: Nações Unidas, 2002.

CERVO, Amado Luiz \& BUENO, Clodoaldo. História da Política Exterior do Brasil. Brasília: Editora da Universidade de Brasília, 2002.

DUROSELLE, Jean-Baptiste. Todo Império Perecerá. Teoria das Relações Internacionais. Brasília: Editora UnB e Imprensa Oficial, 2000.

FROHMANn, Alicia. Puentes sobre la Turbulencia. La Concertación Política Latinoamericana en los Ochenta. Santiago do Chile: FLACSO, 1990. 
GLEIJESES, Piero. The Reagan Doctrine and Central America. Current History. A Journal of Contemporary World Affairs. Vol. 85, n. 515, 1986, p. 401-437.

HALLIDAY, Fred. The Making of the Second Cold War. 2. ed., Londres: Verso, 1986.

IMF. Direction of Trade Statistics Yearbook. Washington: International Monetary Fund, 1986.

IMF. Direction of Trade Statistics Yearbook. Washington: International Monetary Fund, 1992.

IMF. Direction of Trade Statistics Yearbook. Washington: International Monetary Fund, 1996.

LIMA, Maria Regina Soares de. La crisis centroamericana y Brasil: Política reactiva y solidaridad discreta. In: EGUIZÁBAL, Cristina (compiladora). América Latina y la Crisis Centroamericana: En busca de una solución regional. San José: CSUCA, 1990, p. 223-235.

MONIZ BANDEIRA, Luiz Alberto. A Reunificação da Alemanha. Do Ideal Socialista ao Socialismo Real. 2. ed., São Paulo: Global Editora e Brasília: Editora Universidade de Brasília, 2001.

MONIZ BANDEIRA, Luiz Alberto. Relações Brasil-Estados Unidos no contexto da globalização. Vol. II - Rivalidade Emergente. 2. ed., São Paulo: Editora SENAC São Paulo, 1999.

MONIZ BANDEIRA, Luiz Alberto. De Martí a Fidel. A Revolução Cubana e a América Latina. Rio de Janeiro: Civilização Brasileira, 1998.

REINER, Lucio. Como, por que e para que o Brasil enviou tropas à República Dominicana em 1965. Brasília: Tese de Mestrado em Relações Internacionais pela Universidade de Brasília, 1987.

ROUQUIÉ, Alain. Guerras y paz en América Central. Cidade do México: Fondo de Cultura Económica, 1994.

VIZENTINI, Paulo Fagundes. A política externa do regime militar brasileiro. Porto Alegre: Editora da Universidade/UFRGS, 1998.

Resumo

O artigo analisa alguns aspectos da percepção brasileira sobre o conflito regional imperante na América Central, entre 1979 e 1996. Na conclusão sugerese que essa política fundamentou-se no que aqui se chama de a "tese brasileira" sobre a origem, a evolução e os possíveis mecanismos de resolução para o conflito regional.

\section{Abstract}

The article analyzes some aspects of the Brazilian perception about the regional conflict in Central America, between 1979 and 1996. The conclusion 
suggests that the foreign policy towards the conflict was based on the so-called "Brazilian thesis" about the origin, the evolution and the possible mechanisms of solution to the regional conflict.

Palavras-chave: História das Relações Internacionais Contemporâneas da América Latina e do Caribe; Política Externa Brasileira; América Central; Conflito Regional; Segunda Guerra Fria.

Key words: History of Latin America and Caribbean Contemporary International Relations; Brazilian Foreign Policy; Central America; Regional Conflict; Second Cold War. 